Military Technical College

Kobry El-Kobbah,

Cairo, Egypt.

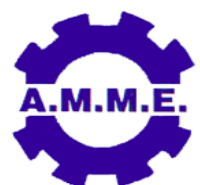

$16^{\text {th }}$ International Conference on Applied Mechanics and Mechanical Engineering.

\title{
ENHANCEMENT OF PROPULSION PERFORMANCE THROUGH JET NOISE REDUCTION TECHNOLOGIES: A REVIEW
}

\author{
T. Raef ${ }^{1}$, A. A. Elzahaby ${ }^{2}$ and M. K. Khalil ${ }^{3}$
}

\begin{abstract}
Jet noise remains a significant noise component in modern aero-engines. A highspeed flow mixing with the surrounding air constitutes noise sources behind the nozzle. One noise-reduction technology is expected to enhance mixing within a limited region downstream of the nozzle. The enhanced mixing leads to the suppression of broadband peak components of jet noise.

The main goal of this paper is to provide an overview of, the aircraft noise generating sources with emphasis on the jet noise, the main technologies employed for control and reduction of aircraft noise, the effect of different techniques and a comparison between them on the flow field and acoustic performance for subsonic and supersonic jets, and finally a survey of the current applications of large-eddy simulation(LES) for predicting of the noise from single stream turbulent jets, including numerical methods for simulation of near and far field of a jet nozzle.
\end{abstract}

\section{KEY WORDS}

Jet noise, Noise reduction, Aircraft noise prediction.

Egyptian Armed Forces. Email: tamerraef1@gmail.com.

2 Professor, Mechanical Power Eng. Dept., Tanta University, Tanta, Egypt. Email: elzahaby47@gmail.com.

3 Egyptian Armed Forces. Email: khilo99@yahoo.com. 


\section{INTRODUCTION}

Modern military aircraft jet engines are designed with variable-geometry nozzles to provide optimal thrust in different operating conditions, depending on the flight envelope. These nozzles increase the complexity and the manufacturing cost. However, acoustic measurements for such nozzles are scarce, due to the cost involved in making full scale measurements and the lack of details about the exact geometries of these nozzles [1]. As military aircraft and engines have grown in performance they have become so loud that the noise they produce presents a health risk to the soldiers, sailors and airmen who work around them as well as a nuisance to those who live or work near military airfields [2].

Noise during airplane take-off is one of the key issues concerning both airframe and aero-engine manufactures. This is a direct consequence of today's rapidly increasing demand for civil air transport. As many new policies and measures have been set out to deal with environmental noise, the drive for aircraft and aero-engine manufactures to develop new conceptual nozzles for quieter engines are emerging [3].

The target to meet noise legislation is an important feature. Noise is generally quantified in decibels $(\mathrm{dB})$, but due to the Committee on Aircraft Noise (CAN) legislation, airport perimeter measurements use the effective perceived noise scale, which was created specifically in order to validate aircraft noise level certification. The decibel addresses a wide range of sound intensities by using a logarithmic ratio of the actual sound pressure level (SPL) to a nominal value. The A-weighted decibel $\mathrm{dB}(\mathrm{A})$ scale is used to determine the degree of irritation to the ear. Alternate noise metrics are used for many applications and for aviation there are two main noise metrics, the first is the A weighted scale, which is used to implement noise restrictions at a number of airports and the second is EPNL. EPNL is the effective perceived noise level, which is a measure of the noise heard on the ground by an observer, corrected for aircraft broadband noise sources as well as the duration of the noise [4].

The growth in the theoretical description of many aero acoustic mechanisms in the past fifty years has been accompanied by a progressive reduction of aircraft noise. Since the Sixties the historical aircraft noise trend shows a reduction of about 20 EPNLdB, mostly due to the progressive introduction into service of high-bypass turbofans and more effective nacelle acoustic treatments. Since the Eighties, however, the noise reduction trend has not been so significant [5].

\section{AIRCRAFT NOISE GENERATING SOURCES}

The noise from aircraft predominately occurs from airframe noise and engine noise. Noise from aircraft systems such as cabin pressurization system, air conditioning systems and auxiliary power unit are also apparent but less so than airframe and engine noise [6]

Airframe noise is the aerodynamic noise generated by all the non-propulsive components of an aircraft [5]. It arises from the airflow around the body of the aircraft 
and its control surfaces such as elevator, rudder and ailerons. This includes 'bluff body noise' caused by vortex shedding from either side of the bluff body such as a landing gear and edge noise caused by the airflow passing over an edge such as a slat. These noise sources are most significant during the approach and are difficult to reduce without considerably affecting the general performance of the aircraft [6].

At take off, engine noise is more dominant than airframe noise. The noise sources here as in Fig.1 and Fig.2, can be subdivided into internally generated noise from the fan(which is generated by the interaction between flow non-uniformities and rotating bladed and stator vanes)[5], compressor noise, combustion noise, turbine blades and other aeromechanical movements and externally generated noise from the mixing of exhaust gases (jet noise) as shown in Fig.3,[6]. In the present paper we focus on the jet noise.

\section{Noise Regulation and Jet Noise}

The current noise levels for noise sources at approach and take off were shown in Fig.4. Prior to the release of the International Civil Aviation Organization (ICAO) Annex 16 certification standards in 2001, research was conducted to investigate the proposed noise cut-backs from independent aviation organizations, such as NASA [7]. Figure.5, describes the targets set by NASA, suggesting limits to reduce the effective perceived noise level by $20 \mathrm{EPNL}(\mathrm{dB})$ within the next twenty years, and an optimistic target of half of this, $10 \mathrm{EPNL}(\mathrm{dB})$, by 2007. The results of the Quiet Aircraft Technology (QAT)research, suggests that individual airframe and engine component noise has met targets, with plans to implement these technologies onto a fleet of aircraft in 2010[8]. Another institution researched was the Advisory Council for Aeronautics Research (ACARE) in Europe. The ACARE targets suggested a reduction of perceived noise of $10 \mathrm{EPNL}(\mathrm{dB})$ by 2020[9].

In the jet flow, there are different noise producing regions as shown in Fig.3, the primary potential core emanates from the core nozzle of the jet and the secondary potential core comes from the bypass nozzle. Both potential cores are high velocity flows with relatively low turbulence, which contribute to the formation of shear layers. That is, since the edge of the primary potential core is travelling faster than the neighboring flow, this causes an inner shear layer to form which encourages the roll up of small vortices as described. The same process occurs with the secondary potential core and the ambient. Generally, the greater the difference between two flows (in terms of their velocity and density), the sharper the interface will be. As the end of the primary potential core slows down, it enters the transition region where turbulent mixing begins. This mixing continues downstream to the developed region where it develops into large scale turbulent mixing [6].

In subsonic jets, the small-scale turbulence is believed to be the dominant source of noise. Even though large-scale coherent turbulent structures and instability waves have been observed in a wide range of Reynolds numbers, these structures are not effective aero acoustic sources. In supersonic jets, even though a direct empirical evidence is difficult to be achieved, large-scale coherent turbulent structures and instability waves are believed to be very effective aero acoustic sources [5]. 
The principal physical difference between the jets emanating from high-performance military jet engines and those from commercial aircraft engines is the presence of shocks in the supersonic former case [10]. There has been significant attention paid to noise from shock containing jets since the 1980s [11]. Broadband ShockAssociated noise (BBSN) is produced by interactions of turbulent large-scale structures convecting in the shear layers with the periodic shock structures in the supersonic jet. The peak frequency of BBSN is a function of angle of observation, shifting to higher frequencies as an observer moves closer to the downstream axis [12]. Screech is understood to be caused by a feedback loop in which BBSN propagating directly upstream interacts with the nozzle exit lip to produce new large scale structures that propagate downstream in the shear layer producing more radiated noise [2].

\section{TECHNOLOGIES FOR NOISE CONTROL AND REDUCTION}

Military aircraft have engines with noise characteristics much louder than civilian aircraft, due to their very low bypass ratios and high exit temperatures and velocities of the jets. The resulted increased noise poses a health threat to ground crews as well as causing an annoyance to communities in the vicinity of military airbases. This has led to the development of noise suppression mechanisms that involve new nozzle design concepts. One idea behind noise reduction concepts is to increase the mixing rate between the jet potential core and the surrounding air flow to shorten the length of the high turbulence and noise producing region [1]

In order to mitigate the noise generation from high-speed jets, several passive and active flow control techniques have been developed and tested in the last years. Passive control is accomplished by modifications of the nozzle shape (e.g. serration, beveling, tabs, etc.). Active control is accomplished by adding mass or energy to the flow in order to suppress flow instabilities or affect the flow through the generation of new flow structures (e.g. stream wise vortices). Active control is further divided into two categories: open-loop and closed-loop. In the open-loop control, actuation takes place based on a predetermined law. In the closed-loop control, real-time information from sensors in the flow is used to drive the actuation process. Only open-loop techniques have been successfully applied to jet noise mitigation [5].

The basic concept behind passive control techniques is the enhancement of jet mixing through the generation of stream wise vorticity. The same concept is applied in open-loop control operated with steady mass or energy injections into the flow, or with pulsating injections at frequencies which are much lower than any instability frequency of the flow. The most popular passive and open-loop active flow control techniques for jet noise mitigation are overlooked in the following sections [5].

\section{Nozzle Tabs and Chevrons}

The rate of mixing of the jet and the surrounding fluid can be increased by the presence of small tabs on the nozzle[13]. Unfortunately, the increased mixing, while reducing low frequency noise, generates excessive high-frequency noise that may overwhelm any acoustic benefit. In addition, tabbed nozzles as shown in Fig.6 always result in thrust loss. As an alternative to tabbed nozzles, serrated nozzles 
edge, or chevrons, have been recently proposed as shown in Fig.7,[14]. These devices are the current state of the art in jet-noise mitigation technology for mediumand high-bypass turbofan engines. Analogously to tabs, the triangular serrations in the nozzle trailing-edge induce stream wise vorticity into the shear layer that leads to increased mixing and reduced length of the jet plume. However, since the penetration into the flow is lower than that occurring with tabs, the mixing enhancement occurs with a minimal engine performance penalty. Experimental tests show a complex dependence of the noise benefits from a series of geometrical parameters, such as the number of chevrons and the level of penetration of the chevrons into the flow. The single and mutual influence of these parameters on the jet noise generation mechanisms is still unclear. Recently, non-uniform circumferential chevron distributions and shapes have been successfully used in order to exploit the circumferential non-uniformity of the flow in realistic installed engine configurations [5].

\section{Distributed Nozzle}

The distributed exhaust nozzle concept is based on the idea that the spectral content of jet noise can be dramatically changed by splitting the exhaust plume through an array of smaller jet plumes [15]. Each plume generates a higher frequency noise, resulting in a global noise benefit, due to the more effective atmospheric absorption at higher frequencies. In addition, if the distributed nozzle assembly is properly designed, the plume coalescence occurs at lower velocity with respect to the single plume exhaust, thus resulting in lower low-frequency noise [5].

\section{Microjet Injection}

The air and water microjet injection is extensively used in the jet noise research area. Water, in particular, is widely used to reduce large pressure fluctuations occurring in supersonic jets[5]. Experimental studies clearly show that the water injection significantly affects the shock cell structures, with consequent benefits on the shock associated noise. Several examples of water microjet injection to supersonic aero-engines jet plumes have been published recently [16],[17], showing reductions in both shock associated noise and Mach wave radiation. The use of passive air microjet injection or synthetic jet actuation show less significant noise benefits [18]. Moreover, open-loop control through unsteady rotating micro jet injections may even result in increased noise levels [19].

\section{Notched Nozzle}

In 2008, the first noise test was conducted on a notched nozzle using a jet engine [20]. The notch, a tiny tetrahedral dent formed at the edge of a nozzle as shown in Fig.8, is expected to enhance mixing within a limited region downstream of the nozzle. The enhanced mixing leads to the suppression of broadband peak components of jet noise with little effect on the engine performance [21]. A 5\% notched (6-notched) nozzle means that the depth of the dent is $5 \%$ of the exit diameter of the baseline nozzle [22]. A 6-notched nozzle was attached to the nozzle end of a turbojet engine. The results showed that this nozzle suppressed broadband noise at middle and lower frequencies; however, additional noise appeared at higher frequencies toward the side direction of the nozzle. The slight penetration of the 
notch causes small disturbances immediately after the nozzle, driving the subsequent mixing process in the shear layer [20]. The enhanced mixing lowers the mean velocity of the jet and prevents the formation of large-scale vortices downstream and excessive shear stress near the nozzle [21].

\section{Ejectors}

Ejector/mixer nozzles have been used for industrial(mixing, jet pump) and aerodynamic(noise suppression, thrust augmentation) applications for many years[23]. An ejector is a fluid dynamic pump with no moving parts. It is relatively simple. The ejector system configuration consists mainly of four parts, namely, the primary nozzle, inlet section, mixing suction and diffuser. In the ejector, the kinetic energy of the primary driving fluid is used to create a low pressure region entraining the secondary fluid stream. Mixing of the two fluid streams occurs in the mixing chamber of the ejector and the resultant fluid mixture is compressed down-stream out in the diffuser. The resulting exhaust jet has a higher flow rate and a lower velocity than the original primary flow[24]. The concept underlying the use ejector/mixer nozzles for aerodynamic applications is driven by two conflicting design requirements. One is to reduce take off noise to an acceptable level, while the other is to maintain a predetermined gross thrust. The conflicting requirements of this problem are revealed by examining the relationship for acoustic power (a measure of noise) $P_{\text {acoustic }} \propto V^{N}$ where $N$ is an exponent varying between ( 3 and 8 ) and $V$ is an ideal exhaust velocity. The smaller value of $N$ corresponds to a fully supersonic jet, while the larger value is that of a fully subsonic jet. Thrust on the other hand may be estimated by the ideal thrust momentum relationship: $F=m V$. Therefore if thrust is to be maximized with exit jet velocity reduction to a minimum, the only term available to control is the mass flow rate, Since ejector nozzles are passive fluid dynamic devices they have potential for providing this mass flow augmentation in a very efficient, reliable manner[23].

\section{REDUCTION OF JET NOISE}

\section{Effect of Nozzle Tab}

The effect of a mechanical tab on the jet development and the acoustical emission of under expanded supersonic jets have been investigated experimentally. It is shown that the jet development is considerably modified by the introduction of the tab in that the shock spacing is shortened and the shock-cell pattern loses axisymmetry and strength. Moreover, the broadband shock-associated noise radiated by the tabbed jet is compared to that of a jet in which screech was suppressed by means of a notched nozzle. The peak frequency of BBSN for the tabbed jet approximately matches that of the notched counterpart, but the amplitude of this noise component was seen to be smaller for the former jet. More importantly, the axisymmetry of the acoustic field is lost when using a tab, resulting in a dependence of measurements on the location of the tab relatively to the microphones. It is concluded that the use of a tab should be avoided to remove screech when studying broadband shockassociated noise [25]. 


\section{Effect of Chevron Parameters}

Experimental investigations have been carried out on chevron nozzles to assess the importance of chevron parameters such as the number of chevrons (chevron count) and chevron penetration[26]. Acoustic measurements such as overall sound pressure level, spectra, directivity, acoustic power, and broadband shock noise have been made over a range of nozzle pressure ratio from sub-critical to under expansion levels. Shadowgraph images of the shock-cell structure of jets from various chevron nozzles have also been captured for different nozzle pressure ratios. The results indicate that a higher chevron count with a lower level of penetration yields the maximum noise suppression for low and medium nozzle pressure ratios. Of all the geometries studied, chevron nozzle with eight lobes and $0^{0}$ penetration angle gives the maximum noise reduction as shown in Fig.9, 10, 11 and 12. Chevron nozzles are found to be free from screech unlike regular nozzles. Acoustic power index has been calculated to quantitatively evaluate the performance of the various chevron nozzles. Chevron count is the pertinent parameter for noise reduction at low nozzle pressure ratios, whereas at high nozzle pressure ratios, chevron penetration is crucial. The results illustrate that by careful selection of chevron parameters substantial noise reduction can be achieved [27].

The comparison between the evaluated values of overall SPL for chevron nozzles having $0^{0}$ and $5^{0}$ taper angles and baseline nozzle for both cold and hot jets was studied. The no penetration chevron nozzle with zero taper angles shows a reduction of approximately $7 \mathrm{~dB}$ and $3 \mathrm{~dB}$ for cold and hot jets respectively. However, the present calculations predict an increase in noise level of $2.5 \mathrm{~dB}$ for chevron nozzle with taper angle $5^{0}$ at all receiver locations for cold jet both at $30 D_{j}$ and $50 D_{j}$ (exit diameter of jet nozzle). In the case of hot jet the forward receivers predicted a reduction in noise level by $1.5 \mathrm{~dB}$, whereas the after receivers showed an increase of $2.5 \mathrm{~dB}$, for the different receivers located at different radii. The chevron nozzle with taper angle $5^{\circ}$ has significantly altered the potential core length, velocity decay, and fluctuating quantities like turbulence intensity and viscosity and this results in increased noise [28].

\section{Effect of Microjet Injection on a Circular Jet Nozzle}

The effect of microjets on subsonic circular jet, focusing on injected mass flux, the number of microjets, the microjets layout and the microjet diameter was presented [29]. Injected several microjets into the supersonic exhaust jet of full-scale F404 engine were studied and the results confirmed with reduction of supersonic jet noise [30]. The effects of microjet under various conditions, comparing those of chevron were studied. It is concluded that microjet could reduce shock-associated noise and screech tone noise mainly and the effectiveness of microjet was highly dependent on the penetration of fluidic injector into the shear layer [31].

\section{Effect of Microjet Injection on a Rectangular Jet Nozzle}

Experimental and numerical investigations were conducted in order to clarify the effect of microjet injection on supersonic jet noise. The experiments were focused on supersonic jet with Mach number up to 1.49 , generated from a rectangular under expanded jet nozzle with high aspect ratio. The microjet injection angle was set to 90 
degrees against the main jet axis. Far field measurements were conducted for the jet noise in the cases with and without microjet injection, and the noise reduction up to $7.5 \mathrm{~dB}$ was obtained [32].

Another investigations were conducted as in [32] but for Mach number up to 1.47 and the injection angle and position of the microjet was changed. Far-field acoustic measurements were conducted for widely ranged microjet conditions to understand the influence of the condition on characteristics of supersonic jet noise and flow field. The conclusions are summarized as the Jet noise was reduced by the use of microjet injection. The reduction of the overall sound pressure level (OASPL) reduced approximately $10 \mathrm{~dB}$. In this case, the mass flux ratio of the microjet of $1 \%$. The broadband peak noise was greatly reduced using microjet injection. The high frequency turbulent mixing noise was, however, increased due to microjet injection in the sideline and backward direction of the main jet. There are an optimum number of microjets. The value of active microjet holes is also an important parameter for reduction of shock-associated noise and screech tone noise [33].

Experimental and numerical investigations were focused on supersonic jet with Mach number up to 1.39, issuing from a rectangular over expanded jet with high aspect ratio. The experiments varied several parameters including main nozzle pressure ratio, total pressure of microjet, number of microjets and microjet injection angle. Jet noise was reduced by microjet injection. The reduction of OASPL was up to $13 \mathrm{~dB}$ with mass flow ratio of $1.5 \%$. The broadband peak noise and screech tone noise were greatly reduced. The high-frequency noise was, however, increased by microjets in some cases. The directivity of the noise showed the similar feature to broadband shock-associated noise. In the case of under-expanded jet, microjet injection to the shear layer out of the main nozzle achieved larger noise reduction than injection into the boundary layer in the nozzle. On the other hand, the results are opposite in the case of over expanded jet. The unsteady flow field visualization showed that microjet suppressed large fluctuations of jet shear layers and the development of large-scale turbulence structures. In the case of under-expanded main jet, shock cell in the jet plume was weakened by microjet injection to the shear layer, while shock cell was strengthened in the case of injection into the boundary layer in the nozzle [34].

\section{Comparison between Chevron and Fluidic Injection}

The observations and simulations of the impact of several technologies (chevrons, fluidic injection and fluidically enhanced chevrons) on modifying the flow field and acoustic emissions from supersonic jets from nozzles typical of those used on military aircraft were presented. The flowfield is measured experimentally by shadowgraph and particle image velocimetry (PIV). The acoustics are characterized by near and far-field microphone measurements. The nozzle geometries used in this research are representative of practical engine nozzles. The near field spectra from (LES) for baseline, chevrons and fluidic injection were shown in Fig.13. This plot shows that chevrons produce a significant reduction in near-field pressure fluctuations below $7 \mathrm{kHz}$. This includes the frequencies at which BBSN peaks are observed in the far field. The emphasis of the work is on "off-design" or non-ideally expanded flow conditions. The fluidic injection geometry and fluidic enhancement geometry follow the approach found successful for subsonic jets employing jets 
pitched $60^{\circ}$ into the flow, impinging on the shear layer just past the tips of the chevrons, or in the same axial position when injection is without chevrons. The principal difference between chevrons and fluidic injection is that for constant injection mass flow the effectiveness of fluidic injection increases with decreasing values of $\mathrm{M}_{\mathrm{j}}$ (Mach Number of Jet Flow) while for chevrons the trend goes the other way [35].

Observations and simulations are presented of a supersonic jet from a nozzle representative of high-performance military aircraft such as the Saab Gripen at the exit of a military jet engine as it departs a runway. The nozzle has a design Mach number of 1.56 and is examined at its design condition with a surrounding secondary flow at Mach numbers of $0.0,0.1$ and 0.3 . Chevrons and internal fluidic injection by microjets each reduce the noise generated by the main jet. A comparison between the footprint reductions for chevrons and microjets was presented. This provides a very practical measure of the effect of noise control on airport neighbors. A reduction of $25 \%$ in the $60 \mathrm{~dB}(\mathrm{~A})$ max contour produced by chevrons means that $25 \%$ fewer houses and people living near a runway will experience a peak level of 60 $\mathrm{dB}(\mathrm{A})$ as a jet leaves the airport. The change due to microjets is even bigger amounting to $38 \%$ fewer annoyed neighbors [2].

\section{Noise Test of Revised Notched Nozzle}

An experimental study on a 6-notched nozzle for jet noise reduction has been performed at an outdoor test site. Tests on the engine include acoustic measurement in the far field to evaluate the noise reduction level with and without the notched nozzle, and pressure measurement near the jet plume to obtain information on noise sources. The far-field measurement indicated the noise reduction by as much as 3 $\mathrm{dB}$ in terms of overall sound pressure level in the rear direction of the engine. The use of the six-notch nozzle though decreased the noise-benefit in the side direction. Experimental data indicate that the high-frequency components deteriorate the noise reduction performance at wider angles of radiation. The penetration of the notches into the jet plume is attributed to the increase in sound pressure level in higher frequencies. The results of near-field measurement suggest that an additional sound source appears up to $x / D=4$ due to the notches [21].

\section{Comparison between Chevron and Notched Nozzle}

The notched nozzle tested in [21] was limited to the cold-jet condition and a 6notched nozzle showed that the notch itself caused additional noise by increasing the sound pressure level at higher frequencies. A revised 18-notched nozzle was developed through computational and experimental studies [20].The hot-jet test was conducted on three types of nozzles: the conical (baseline) nozzle, the referential chevron nozzle with 18 small serrations and the revised finer-notched $3 \%$ (18notched)nozzle. The hot jet test with and without the mixing device served as a compact and flexible test for aerodynamic evaluation of the nozzle. The obtained engine parameters as shown in Fig.14, 15, 16, 17 and18 indicated that the controllability of the engine was sufficient for maintaining identical nozzle pressure ratios (NPRs) among different nozzle geometries. The finer-notched nozzle showed aerodynamic performance that differed from that of the baseline nozzle under identical NPRs, primarily because the effective cross-sectional area was slightly 
smaller than expected. The noise test results under the hot-jet condition with this rig showed that the noise reduction characteristics of the finer notched nozzle are different from those of conventional mixers as in Fig.19. This tendency is apparently related to a mixing feature that causes a moderate mixing process within a longer distance from the nozzle. The noise reduction level was slightly increased toward the side direction, which should reduce the perceived noise level (PNL) at a lateral point during takeoff [22].

A larger-scale nozzle with a diameter five times larger than that in the hot-jet model in [22] was prepared so as to adjust the nozzle aerodynamic performance. Noise tests of this nozzle were carried out using a turbojet engine together with far-field and phased array microphones, where the revised notched nozzle was found to show improved noise reduction performance compared to the previous design [20].

\section{Control Wire Device}

A new technique for the reduction of supersonic jet noise using a control wire device that is placed into the supersonic jet stream. The control wire device is composed of two long stainless cylinders as shown in Fig.20, which have an extremely small diameter (d). Two stainless cylinders are crossed by an angle of $90^{\circ}$. The end of a wire is supported to a rigid cylinder. The rigid cylinder is tightly bolted to the baffle plate installed at the nozzle exit. The location ( $x / D$ ) of the wire device is changed. The center of the wire device is made on the jet axis. The jet pressure ratio is varied to obtain the supersonic jets which are operated in a wide range of over-expanded to moderately under-expanded conditions. A high quality Schlieren optical system is used to visualize the flow field of supersonic jets both with and without the control wire device. The results obtained show that the present wire device effectively breaks the shock-cell structure, reduces the shock strength, and consequently leads to a substantial suppression of supersonic jet noise. The location of the control wire device is an important factor in reducing the supersonic jet noise. The present wire device suppresses the screech tones and the broadband shock-associated noise as well as the overall sound pressure level, when it is placed at a location smaller than three times the exit diameter of nozzle in the downstream of the nozzle exit. For over-expanded jets, the noise control effectiveness of the wire device appears more significant, compared to under-expanded jets [36].

\section{JET PROPULSION PERFORMANCE AND NOISE REDUCTION}

An experimental study is conducted to establish an optimum design of compressible subsonic air ejector as a thrust augmenter and noise attenuator [24] The test rig consists of two reciprocating compressors which compress air to air tank. The air comes from the tank to the settling pipe through the compressed air line. The primary air mass flow rate $\left(\dot{m}_{p}\right)$ is controlled using a valve fitted downstream of tank. The settling pipe was connected to a settling chamber though a divergent section. The settling chamber is connected to a tail pipe through a convergent section. The air from the settling chamber flows to the convergent nozzle via a tail pipe. The air flowing through the nozzle is exhausted to ejector and finally into the atmosphere. The design of ejectors is a complex problem; many geometrical and operational parameters can affect ejector performance. These factors include: ejector length to 
diameter ratios $\left(L_{E} / D_{E}\right)$, ejector area ratio $\left(A R_{E}\right)$, diffuser area ratio $\left(A R_{D}\right)$, halfdivergence angle of the diffuser $(\theta)$, nozzle pressure ratio $\left(\mathrm{P}_{\mathrm{op}} / \mathrm{P}_{\mathrm{atm}}\right)$, total temperature of primary jet $\left(\mathrm{T}_{\mathrm{P}}\right)$ and the axial position of primary nozzle relative to the ejector entry $\left(L_{S}\right)$, Fig.21.

The obtained results show that the optimum thrust augmentation is reached for an ejector with length to diameter ratio $L_{E} / D_{E}=7$, mixing suction to nozzle exit area ratio $A R_{E}=22, A R_{D}=1.6, \theta=6^{0}, L_{S}=-0.5$ (the nozzle outside the ejector). Under these conditions the thrust augmentation ratio $\phi=1.49$ with noise attenuation decreased by $0.7 \mathrm{~dB}$. The optimum noise attenuation is achieved for an ejector with $L_{E} / D_{E}=9, A R_{E}=36, A R_{D}=1.8, \theta=4^{0}, L_{S}=0.75 D_{E}$ (the nozzle inside the ejector). Under these conditions the noise attenuation decreased by $8.1 \mathrm{~dB}$ with thrust augmentation ratio $\phi=1.12$. The optimum design for noise attenuation and thrust augmentation is achieved for an ejector with $L_{E} / D_{E}=7, A R_{E}=22, A R_{D}=1.6$, $\theta=4^{0}, L_{S}=0$. Under these conditions the noise attenuation decreased by $4.8 \mathrm{~dB}$ with thrust augmentation ratio $\phi=1.36$ [24].

\section{NUMERICAL SIMULATIONS AND ACOUSTIC MODELING TECHNIQES FOR JET NOISE PREDICTION}

The main advantage of using CFD is the relatively low cost of the computational prediction in comparison with alternative experimental investigations [37]. In addition, Simulations and observations provide complementary information about the flowfield and near-field around the jet. The simulations, once validated, illuminate portions of the flow-field which are difficult to measure in a non-intrusive manner[38]. Observations of near-field pressure, for example, can be made near the jet, but not in it, while simulations give pressure values both in and near the jet. Simulations also provide all flow variables in a correlated fashion, while measurements are often uncorrelated with different quantities measured on different days. Capturing highgradient features like shocks requires that the simulations employ fine grids, driving up the over-all cell count. Confining the computational domain to an area around the jet itself limits computational cost, while it is convenient to take experimental measurements farther from the jet. Simulations must be validated in order to be trustworthy, and high-quality measurements provide the data necessary to validate the simulations [2].

\section{Near and Far Field Noise Prediction}

LES has proved to be a fruitful tool in investigating the flow-field and near-field acoustics of supersonic jets. LES may be combined with acoustic extrapolation methods to predict far-field acoustic effects[2]. LES is a numerical method that can predict the effect of noise reduction concepts on jet noise sources such as Eddy Mach Wave radiation, broadband shock associated noise, and jet screech[39]. However, propagating the sound waves to the far-field with LES is still too expensive due to grid resolution limitations. The noise in the far-field is predicted with a transformation using the Ffowcs Williams and Hawkings (FW-H) equation [40].

Modern military aircraft jet engines are designed with variable-geometry nozzles. The acoustic field produced by supersonic jets issuing from converging-diverging 
military style nozzles are studied to identify and test promising noise reduction techniques. A new methodology for using data obtained from testing at small and moderate scales, supported by computations, to reliably predict the full-scale engine noises. The experimental results presented show reasonable agreement between small-scale and medium-scale jets, as well as between heated jets and heatsimulated ones [1].

\section{Effect of grid refinement}

The supersonic jet exhaust is simulated using LES, and the FW-H equation transforms the LES solution to an acoustic solution in the far-field. Acoustics Research Tunnel is used as validation for the LES/FW-H method. A grid refinement study was performed with the objective of determining the requirements for accurate noise predictions. The finest grid resolution yields the best near and far-field acoustic prediction. A second LES/FW-H validation case for a twin jet experiment that was performed in the anechoic chamber for Physical Acoustics. The LES/FW-H method is applied to the higher complexity heated twin jet with faceted nozzle profiles, demonstrating the applicability of the method over a wider range of flow regimes. The far-field noise prediction agrees very well with the experimental measurements, including the prediction of broadband shock associated noise and jet screech [40].

\section{Domain and boundary conditions}

A new strategy regarding the simulation of sound generation and propagation is presented. A domain decomposition approach is used for the simulation of an aero acoustic problem. The basic concept is to combine adapted numerical methods, equations, grids and even time steps for a greater efficiency. This aero acoustic coupling is based on the splitting into noise sources generation and acoustic propagation in separate physical domains. The key idea is to limit, as much as possible, the CFD domain to the noise generation region that is often confined in a small part of the flow field, and to accurately propagate the acoustic waves with a Computational Aero Acoustics (CAA) solver. Generally, such a reduction of the CFD domain requires coupling the CFD and CAA computations with an exchange boundary located within the turbulent flow. This splitting method is applied to a hot jet simulation [41].

The importance of initial conditions on subsonic jet noise is emphasized by showing numerical results obtained by large-eddy simulations for initially laminar round jets. The near and the far sound pressure fields of the jets are found to significantly vary with the flow parameters, namely the boundary-layer thickness and the turbulence levels, at the nozzle exit. With respect to initially turbulent jets, strong additional noise components generated by pairings of coherent vertical structures in the transitional shear layers are in addition observed, in agreement with experiments [42].

An accurate LES requires the definition of suitable initial and boundary conditions [43]. Three different techniques were investigated to evaluate different methods for generating turbulent inflow data for the Large Eddy Simulation of turbulent flows. The investigated methods are Filtered noise (FN), Diffused noise (DN) and an Inverse Fourier approach (IF). Digital filtering (FN) of random data is used in the first approach. In this way large scale structures are generated from the random data. The application of a diffusion operation affects white noise in a similar way and is 
used as second inflow generation method (DN). Both FN and DN create spatial correlations in initially fully randomized data fields. The third algorithm (IF) makes use of a prescribed energy spectrum function. The fluctuation field is obtained from a Fourier series. The turbulent statistics i.e. energy spectra and velocity correlations as well as derived quantities such as turbulent kinetic energy and subgrid scale viscosity are investigated. The results are analyzed such that turbulence fluctuations generated by filtered noise and diffused noise lead to similar results. The resulting energy spectra and velocity correlations agree generally well with experimental data despite some discrepancies at very early times after initialization. The Inverse Fourier approach yielded good agreement at all times, but at increased computational cost. In addition, the implementation of Filtered noise and Diffused noise might be easier for most cases of practical interest [44].

\section{Simulation methodology}

The application of Reynolds-averaged Navier-Stokes based methods (RANS) to the investigation of flow and acoustic fields for two nozzles with different chevron geometries was presented. Results for the fluid flow were obtained with a cubic $k-\epsilon$ turbulence model and showed reasonable agreement with the experimental data for both nozzle geometries. The deviations observed in the fluid flow predictions are due to the well-known intrinsic limitations of RANS turbulence models when applied to jet flow [45].

Although in-depth analysis of chevrons for realistic military gas turbine engines has been performed in the past with RANS CFD [46], limited work has been performed for chevrons using the LES/FW-H methodology until now [47]. The observations on the impact of mechanical chevrons on modifying the flow field and noise emanated by supersonic jet flows were presented. These observations are derived from both a monotonically integrated large-eddy simulation (MILES) approach to simulate the near fields of supersonic jet flows and laboratory experiments. The nozzle geometries used in this research are representative of practical engine nozzles. A finite-element flow solver using unstructured grids allows us to model the nozzle geometry accurately and the MILES approach directly computes the large scale turbulent flow structures. The shock cell spacing and the length of the potential core increase as the nozzle pressure ratio increases. The general features of the flow field and the differences observed between under- and over-expanded jets are in good agreement with experimental observations. The impact of mechanical chevrons on modifying the flow field and hence the near-field acoustics was investigated. Current results show that chevrons cause the shock cells to move closer to the nozzle and reduce the spacing between them. In addition, they induce more spread of the jet flow and decrease the strength of the shock cells. A general reduction in the sound pressure level is also observed [48].

The LES numerical system is then used to explore the relatively new "microjet" noise reduction concept (injection of high-pressure microjets in the vicinity of the main jet nozzle exit), which currently attracts significant attention in the aero acoustic community. The simulations are found to capture the essential features of the flow/turbulence and the far-field noise alteration by the microjets are observed in experiments, and to reveal the subtle flow features responsible for the effect of injection on noise. They also confirm the experimental observation that in static conditions microjets provide a noise reduction comparable with that from chevrons in 
the low-frequency range, and probably have a less pronounced high-frequency penalty. This positive evaluation of the microjets concept is, however, mitigated by results of simulations in flight conditions [49].

An FW-H based methodology has been presented for noise prediction in subsonic heated jets, with unsteady Reynolds stress model, where RANS solutions for twodimensional and full three-dimensional representations used as the input to the noise model. The noise predictions are also compared with experimental measurements. The three-dimensional simulation results are in good agreement with data for all frequencies investigated, while the two-dimensional results show good agreement with the measured noise for low frequencies, but fail to predict noise correctly for high frequencies. This discrepancy might be caused by the numerical grid resolution employed. In addition, the results are compared with noise predictions obtained for the jet based on ( $k-\epsilon)$ RANS flow field modeling and a physics-based jet noise prediction code, JeNo (NASA), and also with a modified version. FW-H model fails to capture correctly noise levels at high frequencies, the simulation results at low frequencies demonstrate remarkably good agreement with experimental data. In contrast, the modified JeNo approach is in good agreement with data at high frequencies, but is less so at low frequencies. Coupling these two approaches to provide a rapid means of accurately predicting noise levels over all frequencies may therefore be a viable approach. However, in general, the three-dimensional FW-H approach would appear, from the comparisons presented, to offer a more generally applicable, although computationally intensive, method for jet noise simulations [37].

Numerical simulations of round, compressible, turbulent jets using the Shear Stress Transport (SST $k-\omega$ ) model have been carried out. The three-dimensional calculations have been done on a tetrahedral mesh with 0.9 million cells. Two jets, one cold and hot, have been simulated. The Mach number for both the cases is 0.75 . Overall sound pressure levels (SPL) at far-field observer locations have been calculated using FW-H equation. The numerical predictions have been compared with experimental results. Axial and radial variation of the mean axial velocity and overall SPL levels are compared. The potential core length is predicted well, but the predicted centerline velocity decay is faster than the measured value. The Unsteady Reynolds-averaged Navier-Stokes based methods (URANS) calculations are not able to predict the absolute values for the overall SPL, but predict the trends reasonably well. The calculations predict the trends and absolute values of the variations of the spectral amplitude well for the aft receivers, but not for the forward receivers [28].

\section{CONCLUSION}

Chevrons typically reduce the low-frequency noise observed downstream (at low polar angles) while increasing the high-frequency perceived by an observer orthogonal to the jet axis (polar angle $90^{\circ}$ ).

Chevron count controls the spacing between the axial vortices generated by the chevrons. Penetration controls the strength of the axial vorticity. Length controls the distribution of vorticity within the axial vortices. The no penetration chevron nozzle 
with zero taper angles shows a reduction of approximately $7 \mathrm{~dB}$ and $3 \mathrm{~dB}$ for cold and hot jets respectively.

The principal difference between chevrons and fluidic injection is that for constant injection mass flow the effectiveness of fluidic injection increases with decreasing values of Mach Number of Jet Flow while for chevrons the trend goes the other way. The reduction of OASPL according to the fluidic injection was up to $13 \mathrm{~dB}$.

A revised 18-notched nozzle increased the noise reduction up to $3 \mathrm{~dB}$ under both cold and hot-jet conditions. The finer-notched nozzle showed aerodynamic performance that differed from that of the baseline nozzle under identical NPRs, primarily because the effective cross-sectional area was slightly smaller than expected. The finer notched nozzle contributes more to noise reduction at higher emission angles. The referential chevron nozzle shows benefits at lower emission angles.

The ejectors are developed and applied for gas turbine engines, to generate effective exhaust noise attenuation without losing the thrust, but even if possible with thrust increase.

The LES solves the noise generating regions of the flow in the nearfield, and the $\mathrm{FW}-\mathrm{H}$ transformation is used to predict the far-field noise. The exponential growth in supercomputing power is allowing for highly resolved LES calculations with increasing grid sizes and complexities. The implementation of the $\mathrm{FW}-\mathrm{H}$ equation method predicts the acoustic signature at locations beyond the extent of the LES domain. This greatly reduces the grid resolution requirements.

The FW-H, three-dimensional URANS approach demonstrates a good capability as a universal tool for noise simulations as it does not require any specific modifications to the acoustic model to correctly predict the noise from hot jets. Because the threedimensional FW-H approach is more expensive from a computational point of view than its two-dimensional counterpart, two-dimensional computations are worthy of consideration.

\section{REFERENCES}

[1] J. V. a. D. K. M. Ching-Wen Kuo, "Acoustic measurements of models of military style supersonic nozzle jets," Chinese Journal of Aeronautics, 2014.

[2] D. C. David Munday, Michael Perrino, Ephraim Gutmark, Markus O. Burak and Lars-Erik Eriksson, "Techniques for supersonic turbojet noise reduction," ASME, 2012.

[3] P. G. T. a. S. E. Hao Xia, "Large-eddy simulations of chevron jet flows with noise predictions," ASME, 2009.

[4] S. MISTRY, "A novel airframe design methodology for silent aircraft " 2008.

[5] F. D. D. Casalino, R. Sannino and A. Paonessa, "Aircraft noise reduction technologies: A bibliographic review," Aerospace Science and Technology, 2008.

[6] A. Kiran, "Jet noise: aeroacoustic distribution of a subsonic co-axial jet," 2008. 
[7] I. C. A. O. (ICAO), "Environmental protection annex 16 chapter 4," International Standards and Recommended Practices, 2001.

[8] ICAO, "Environmental technical manual on the use of procedures in the noise certification of aircraft," 1995.

[9] T. O. Nozomi TANAKA, Yoshinori OOBA, Shunji ENOMOTO, Kazuomi YAMAMOTO and Tatsuya ISHII, "Experimental and computational approach for jet noise mitigation by mixing control devices," ASME, 2011.

[10] J. Panda, "Identification of noise sources in high speed jets via correlation Measurements - a review," AIAA, 2005.

[11] R. Schlinker, "Supersonic jet noise from round and chevron nozzles: experimental studies," AIAA, 2009.

[12] R. Schlinker, Simonich, J. and Reba, R, "Flight effects on supersonic jet noise from chevron nozzles," AIAA, 2011.

[13] B. C. a. E. Gutmark, "Far-field acoustic investigation into chevron nozzle mechanisms and trends," AIAA, 2005.

[14] K. K. B. Henderson, J. Whitmire and A. Abeysinghe, "The impact of fluidic chevrons on jet noise," AIAA, 2005.

[15] K. K. A. R.J. Gaeta, D.B. Schein and W.D.J. Solomon, , "Large jet-noise reductions through distributed nozzles," AIAA, 2002.

[16] B. G. a. A. Krothapalli, "Jet noise reduction using aqueous microjet injection," AIAA, 2004.

[17] T.D. Norum, "Reduction in multi-component jet noise by water injection," AIAA, 2004.

[18] A. K. B. Greska, N. Burnside and W.C. Horne, "High-speed jet noise reduction using microjets on a jet engine," AIAA, 2004.

[19] R. K. a. Y. N. M.K. Ibrahim, "Mixing enhancement of compressible jets by using unsteady microjets as actuators," AIAA, 2002.

[20] N. T. Tatsuya Ishii, Tsutomu Oishi and Yutaka Ishii, "Noise test of revised notched nozzle using a jet engine " ASME, 2013.

[21] H. O. T. Ishii*, K. Nagai, N. Tanaka, Y. Oba and T. Oishi, "Experimental study on a notched nozzle for jet noise reduction " ASME, 2011.

[22] N. T. Tatsuya Ishii, Hideshi Oinuma and Tsutomu Oishi, "Hot-jet noise test of a revised notched nozzle," ASME, 2012.

[23] L. J. D. C. a. J. A. Seidel, "Analytical development of non- ideal effects for control volume based mixer models," Aerospace Science and Technology, 2001.

[24] E. A. E. S. A.M. EL Zahaby, A.E. Kabeel, A.I. Bakry and Z.M. Omara, "Noise attenuation and associated thrust increase by using the ejectors," $6^{\text {th }}$ International Engineering Conference. Mansora University, 2008.

[25] T. a. C. B. Benoît André, "Effect of a tab on the aerodynamical development and noise of an underexpanded supersonic jet," Comptes Rendus Mecanique, 2013.

[26] S. Martens, "The effect of chevrons on crackle engine and scale model results," ASME, 2011.

[27] P. S. T. a. K. Srinivasan, "Effect of chevron count and penetration on the acoustic characteristics of chevron nozzles," Applied Acoustics, 2010.

[28] P. S. T. a. V. Babu, "Numerical predictions of noise due to subsonic jets from nozzles with and without chevrons," Applied Acoustics, 2009.

[29] T. Castelain, Sunyach, M, Juve, D and Bera, J, "Effect of microjets on a highsubsonic jet. parametric study of farfield noise reduction," AIAA, 2006. 
[30] B. a. K. Greska, A, "The effects of microjet injection on an 4404 jet engine," AIAA, 2005.

[31] D. R. Cuppoletti, T., Perrino, M. and Gutmark, E, "Injection effects on acoustics of a supersonic jet at various mach numbers," AIAA, 2011.

[32] T. W. Ryuichi Okada, Seiji Uzawa, Takehiro Himeno and Tsutomu Oishi and "Investigation of microjet injection for reduction of supersonic jet noise " ASME, 2010.

[33] T. W. Ryuichi Okada, Seiji Uzawa, Takehiro Himeno and Tsutomu Oishi, "Influence of microjet condition on characteristics of supersonic jet noise and flow field " ASME, 2012.

[34] T. W. Ryuichi Okada, Seiji Uzawa, Takehiro Himeno and Tsutomu Oishi, "Suppression of supersonic jet noise from rectangular nozzle by microjet injection: influence of main jet condition " ASME, 2013.

[35] N. H. David Munday, Ephraim Gutmark, Junhui Liu and K. Kailasanath, "Supersonic jet noise reduction using fluidics, mechanical chevrons and fluidically enhanced chevrons," ASME, 2010.

[36] Y. M. Y.-H. Kweon, T. Aoki, H.-D. Kim and T. Setoguchi, "Control of supersonic jet noise using a wire device," Journal of Sound and Vibration, 2006.

[37] M. F. a. M. P. T. Stanko. D. B. Ingham, "Application of rans and fwh modelling to the prediction of noise From round jetsfrom round jets," ASME, 2009.

[38] B. J. Boersma, and Lele, S. K, "Large eddy simulation of a mach 0.9 turbulent jet," AIAA, 1999.

[39] G. S. Constantinescu, and Lele, S. K, "Large eddy simulation of a nearly sonic turbulent jet and its radiated noise,," AIAA, 2001.

[40] J. P. E. a. N. Sinha, "Near and far-field investigations of supersonic jet noise predictions using a coupled les and fw-h equation method," ASME, 2011.

[41] C. P. O. Labbé, G. Rahier and M. Huet, "A CFD/CAA coupling method applied to jet noise prediction," Computers \& Fluids, 2013.

[42] C. B. a. C. Bailly, "On the importance of specifying appropriate nozzle-exit conditions in jet noise prediction," Procedia Engineering, 2010.

[43] E. L. a. D. L. Billson M, "Jet noise prediction using stochastic turbulence modeling," AIAA, 2003.

[44] D. M. Dirk Dietzel, Federico Piscaglia, Andrea Montorfano, Gregor Olenik, Oliver T. Stein, Andreas Kronenburg, Angelo Onorati and Christian Hasse, "Evaluation of scale resolving turbelance generation methods for large eddy simulation of turbulent flows," Computers \& Fluids, 2014.

[45] C. R. I. S. a. C. J. D. Rafael C. Engel, "Application of RANS-based method to predict acoustic noise of chevron nozzles," Applied Acoustics, 2013.

[46] C. Kannepalli, Kenzakowski, D., and Dash, S., "Evaluation of some recent jet noise reduction concepts," AIAA, 2003.

[47] N. Sinha, Kenzakowski, D., Ungewitter, R., Dash, S., and Seiner, J, "Computational and experimental investigations of jet noise reduction concepts for low bypass ratio military gas turbine engines," ASME, 2008.

[48] J. L. K. Kailasanath, Ephraim Gutmark, David Munday and Steven Martens, "Impact of mechanical chevrons on supersonic jet flow and noise " ASME, 2009.

[49] P. R. S. a. M. K. S. Mikhail L. Shur, "LES-based evaluation of a microjet noise reduction concept in static and flight conditions," Journal of Sound and Vibration, 2011. 


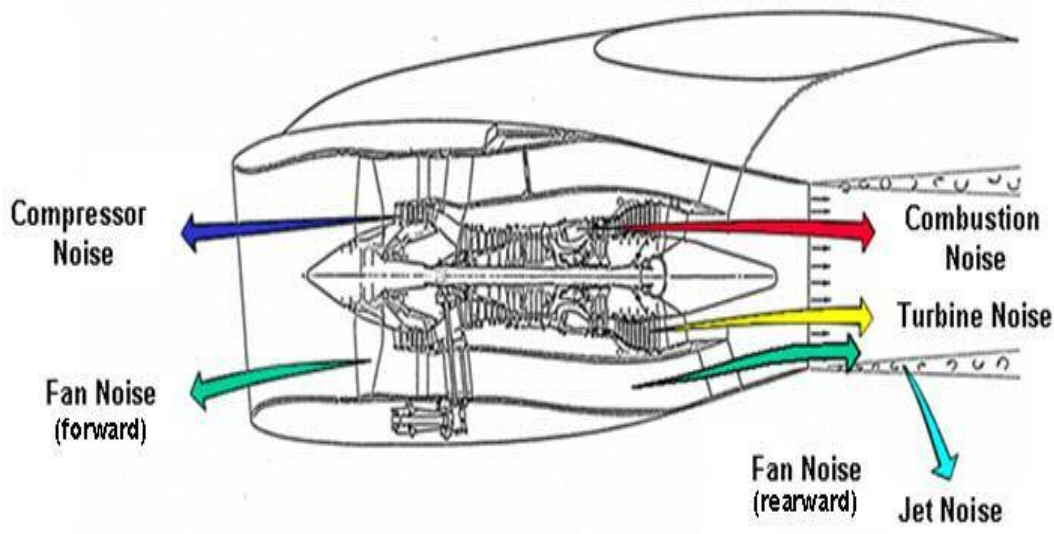

Fig.1. Noise sources of a turbofan engine.

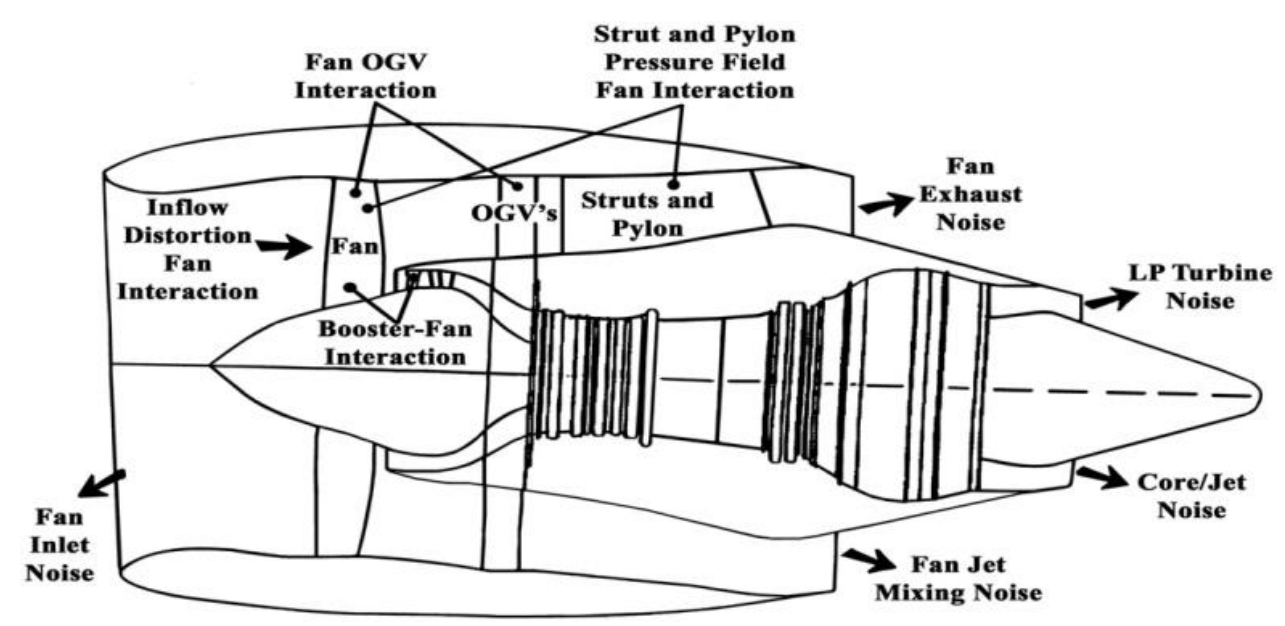

Fig.2. Noise generating mechanisms in turbofan engines.

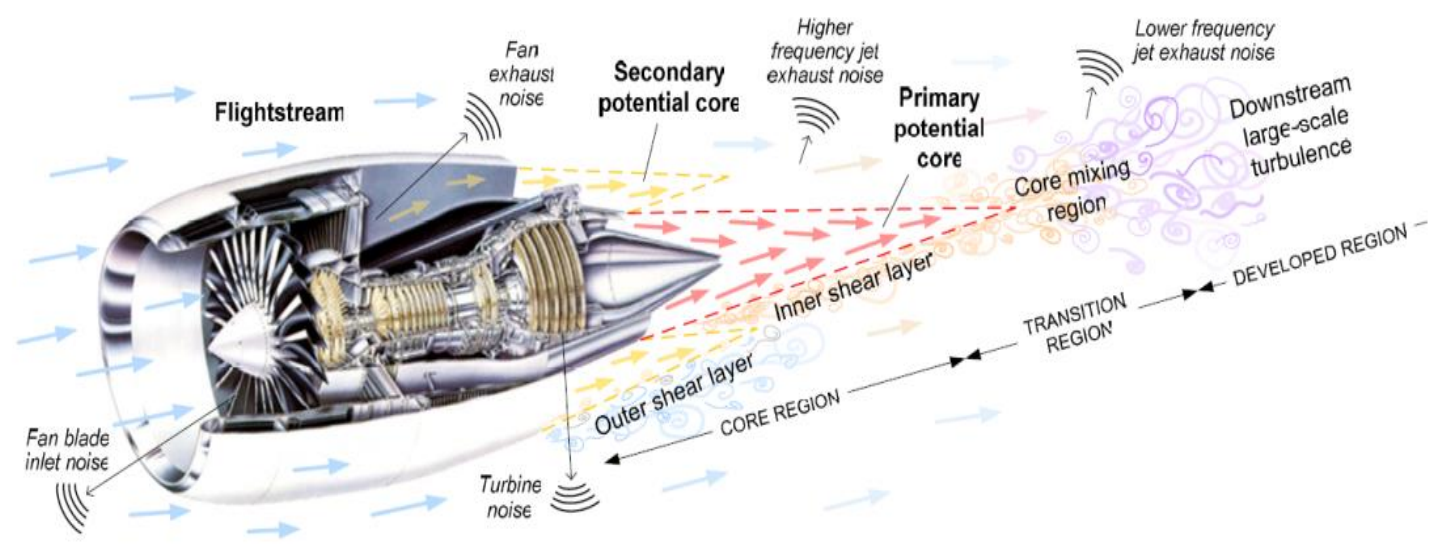

Fig. 3. Jet noise mixing regions. 


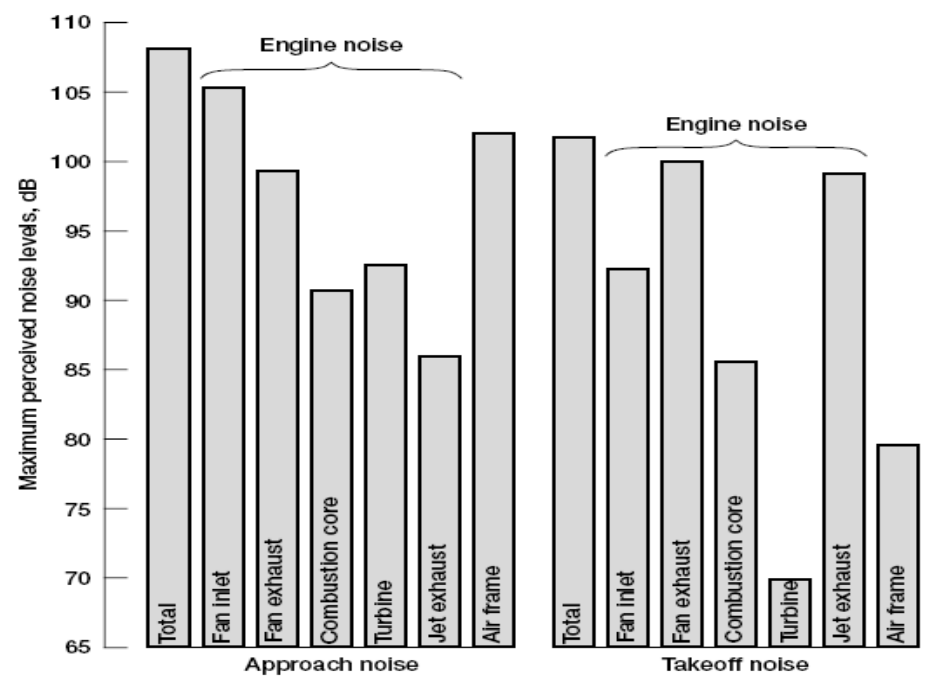

Fig. 4. Current noise levels for noise sources.

\section{Global Civil Aviation Noise Goals}

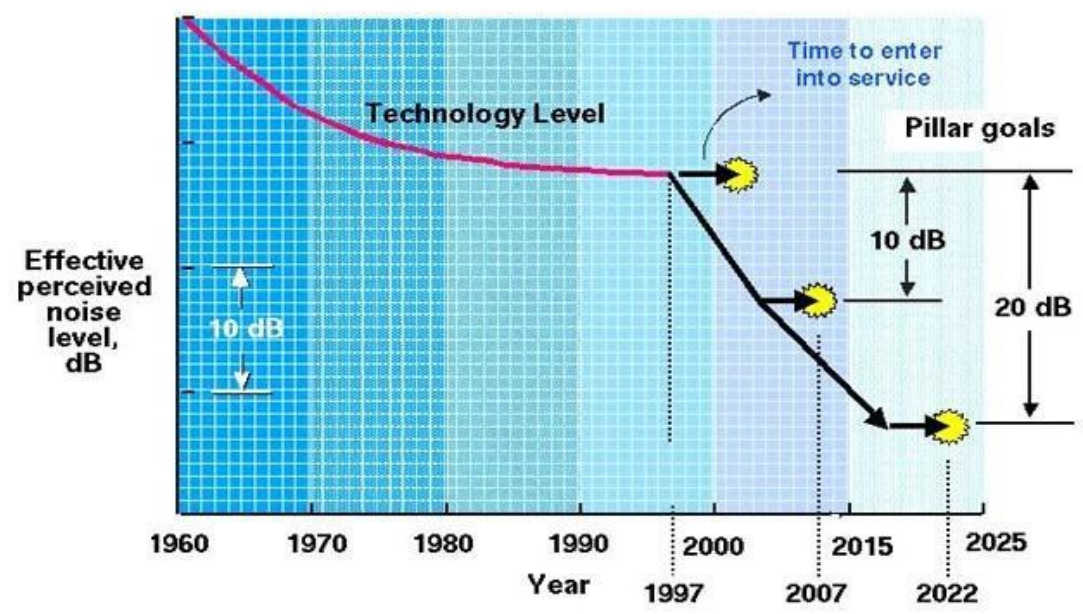

Fig. 5. Aviation Noise Goals extracted from NASA future noise targets.

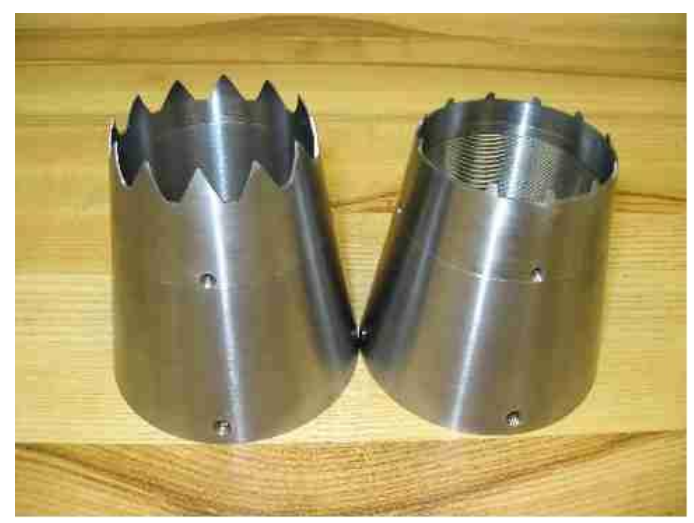

Fig. 6. Nozzle tabs (right) and chevron (left). 

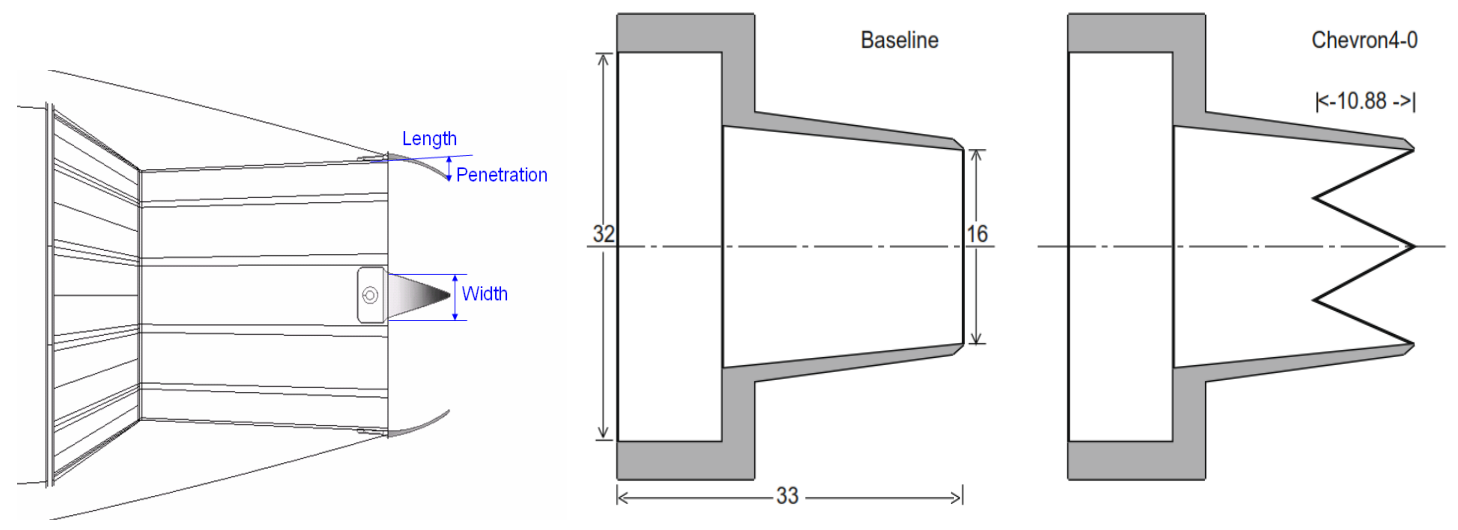

Fig.7. Geometry of chevron nozzle.
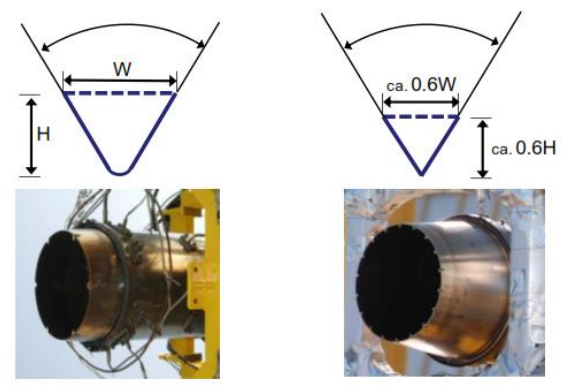

Fig. 8. Notched nozzles, Left:6-notched nozzle, Right : 18 notched nozzle.
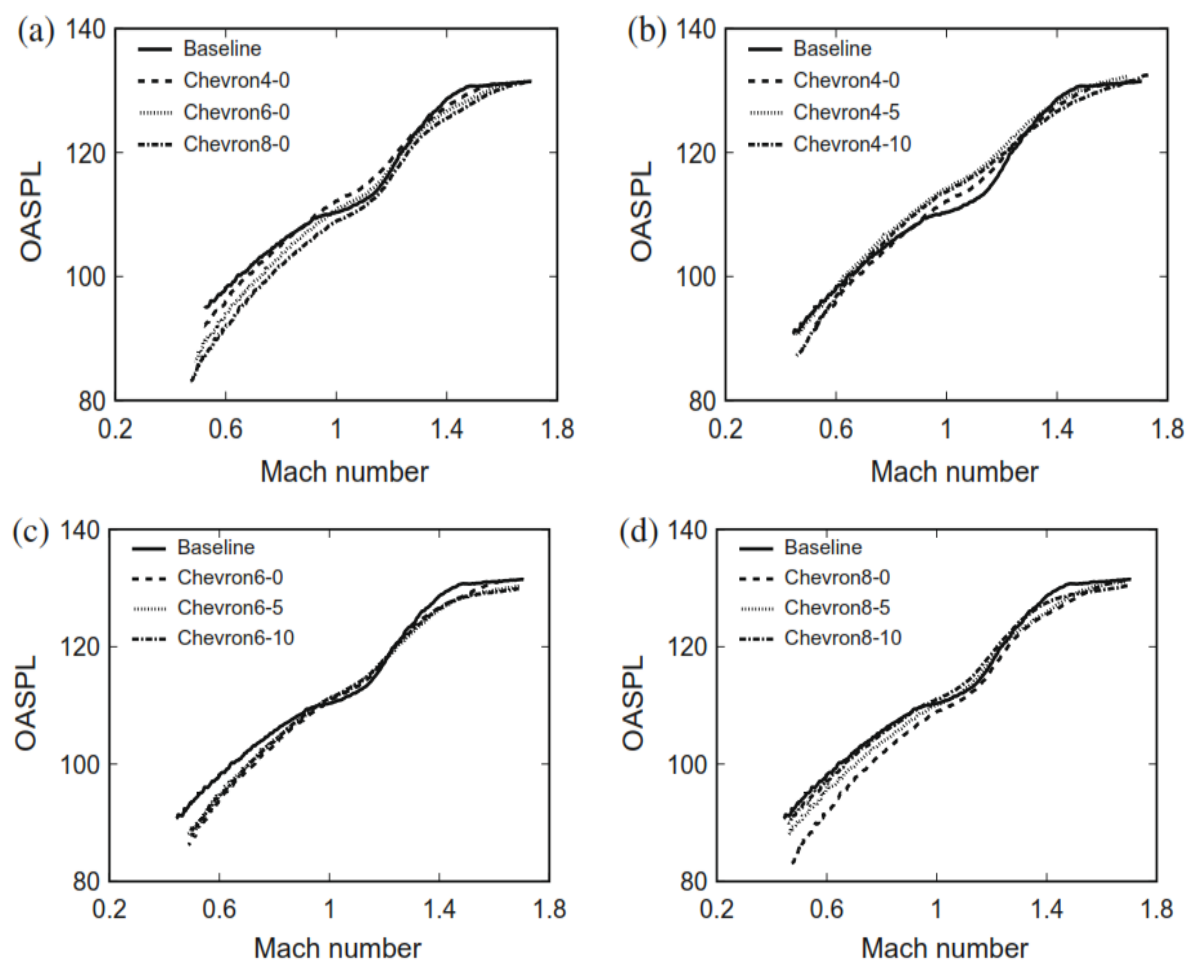

Fig. 9. Variation of overall sound pressure level with Mach number during blowdown. 
NPR-3.0

(a)

$\times$ Baseline Chev4-0 $\Delta$ Chev6-0 $\nabla$ Chev8-0 NPR -3

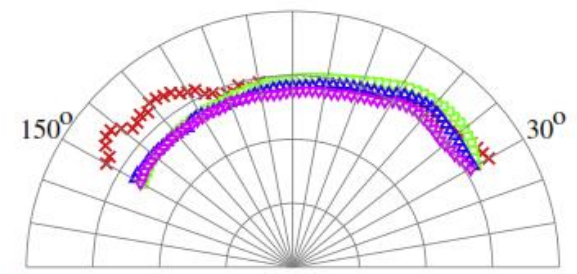

140

80
SPL $(d B)$

(c)

$\times$ Baseline $\square$ Chev6-0 $\triangle$ Chev6-5 $\nabla$ Chev6-10

NPR -3

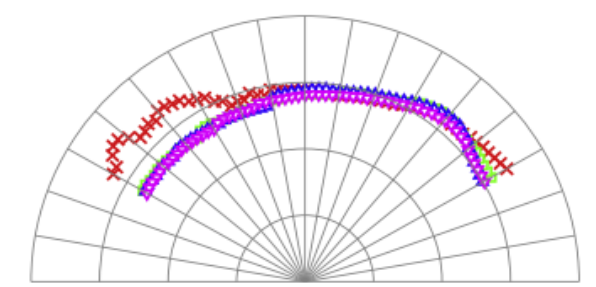

140
80

SPL (dB) (b)

$\times$ Baseline $\square$ Chev4-0 $\Delta$ Chev4-5 $\nabla$ Chev4 -10

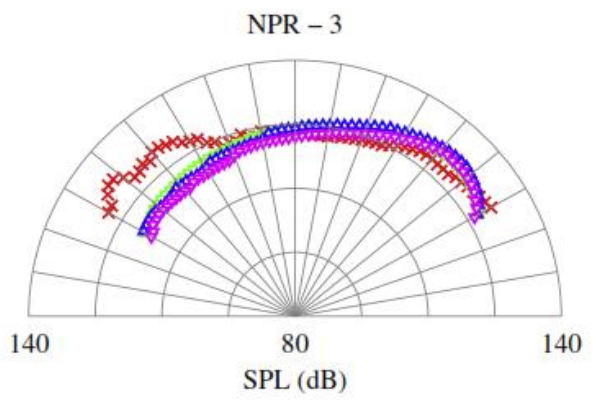

(d)

$\times$ Baseline $\square$ Chev8-0 $\Delta$ Chev8-5 $\nabla$ Chev8-10 NPR -3

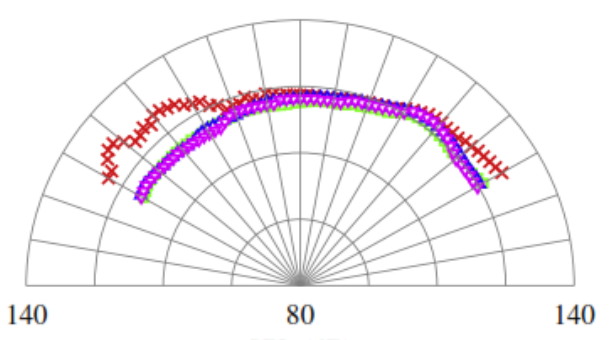

SPL (dB)

Fig. 10. Directivity of sound pressure for NPR $=3.0$.

NPR-4.5

(a)

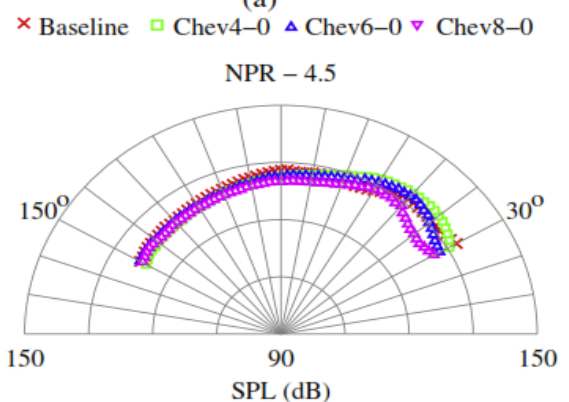

(c)

$\times$ Baseline $\square$ Chev6-0 $\Delta$ Chev6-5 $\nabla$ Chev6-10

NPR -4.5

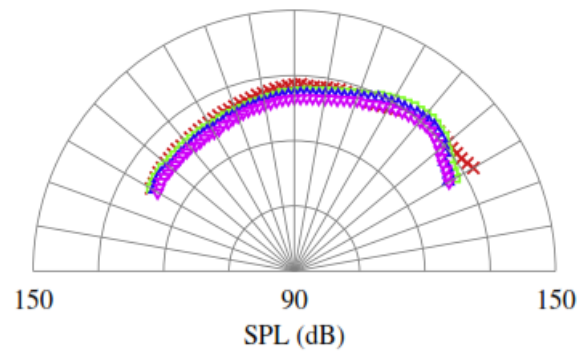

(b)

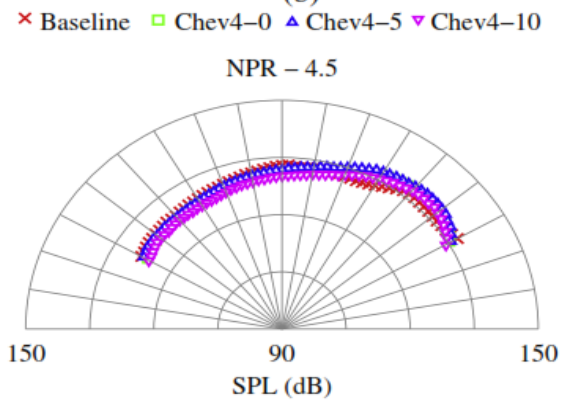

(d)

$\times$ Baseline $\square$ Chev8 $-0 \Delta$ Chev8-5 $\nabla$ Chev8-10

NPR -4.5

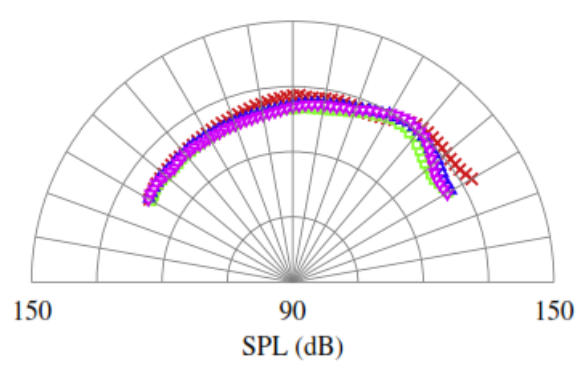

Fig. 11. Directivity of sound pressure for NPR $=4.5$. 

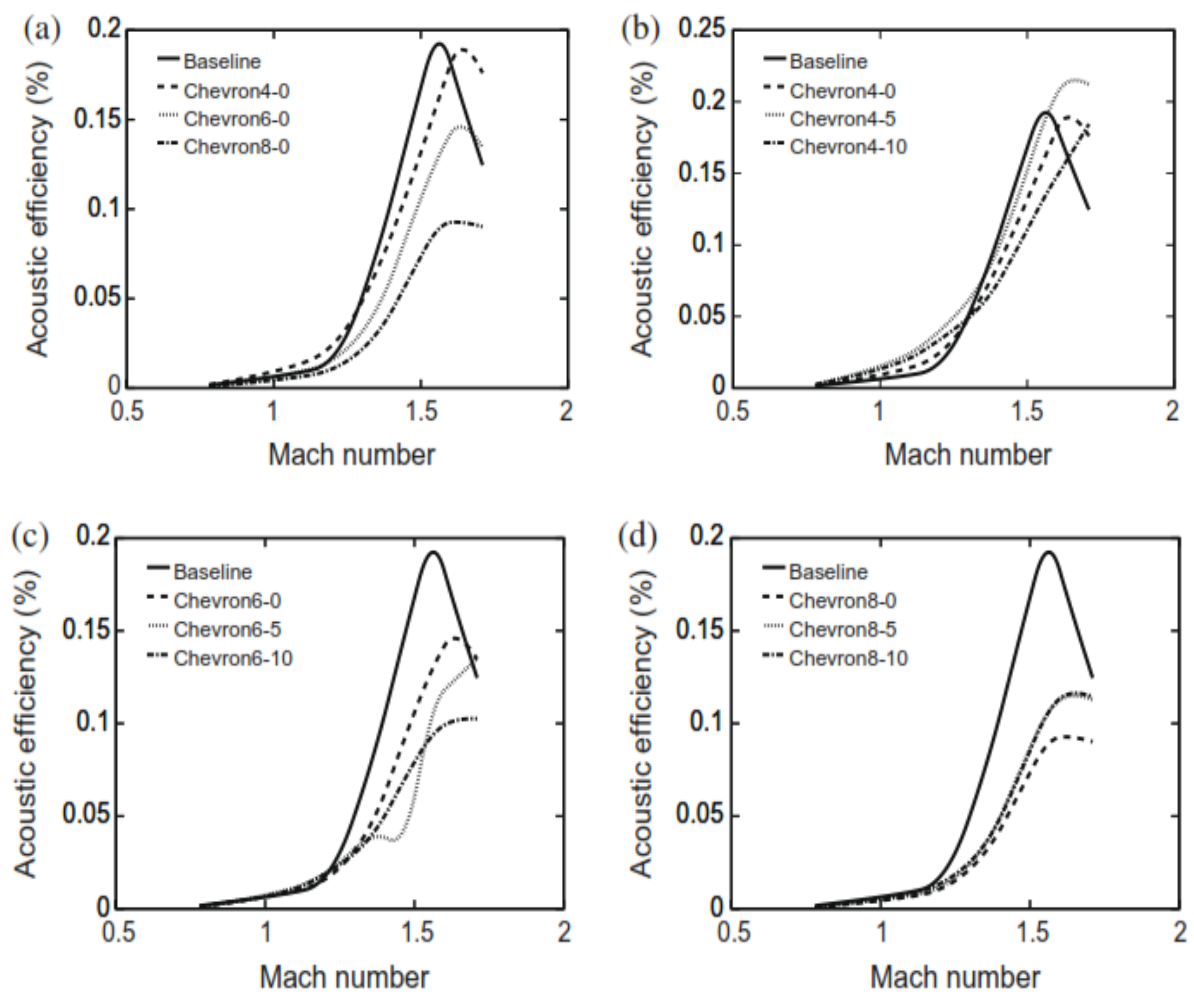

Fig.12. Variation of acoustic efficiency with Mach number.
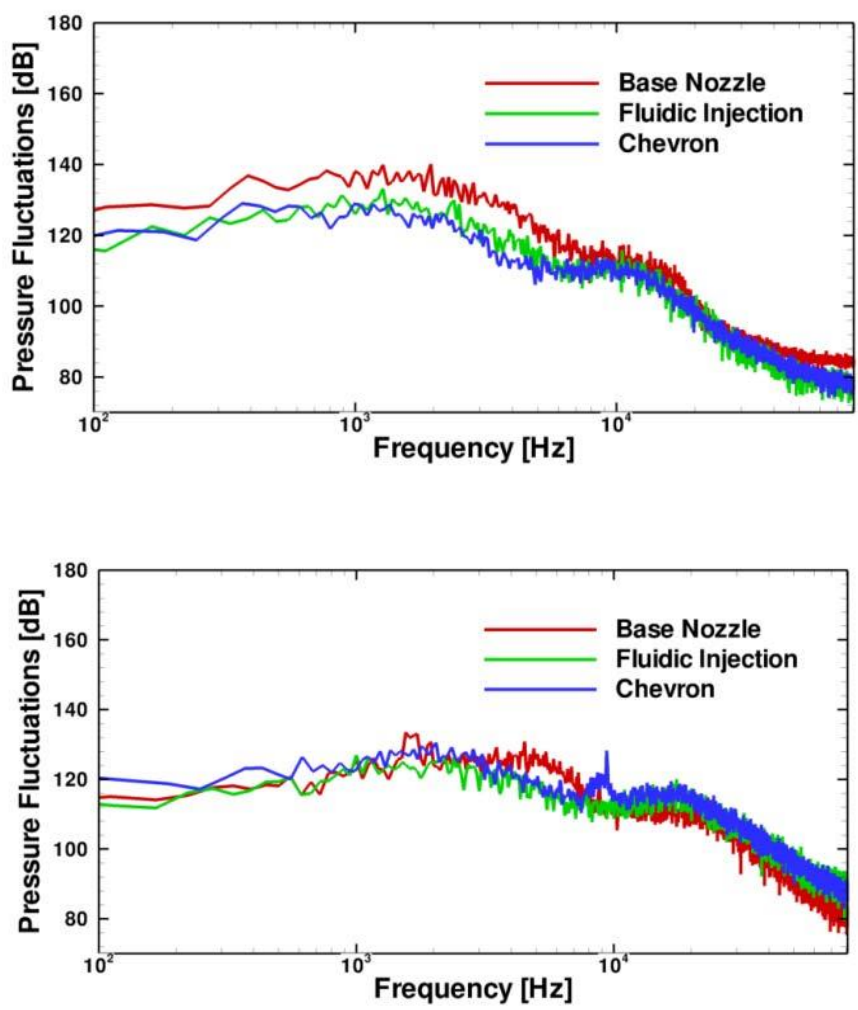

Fig.13. Near-field spectra from LES for baseline, chevrons And fluidic injection $\mathrm{M}_{\mathrm{j}}=1.56$. 

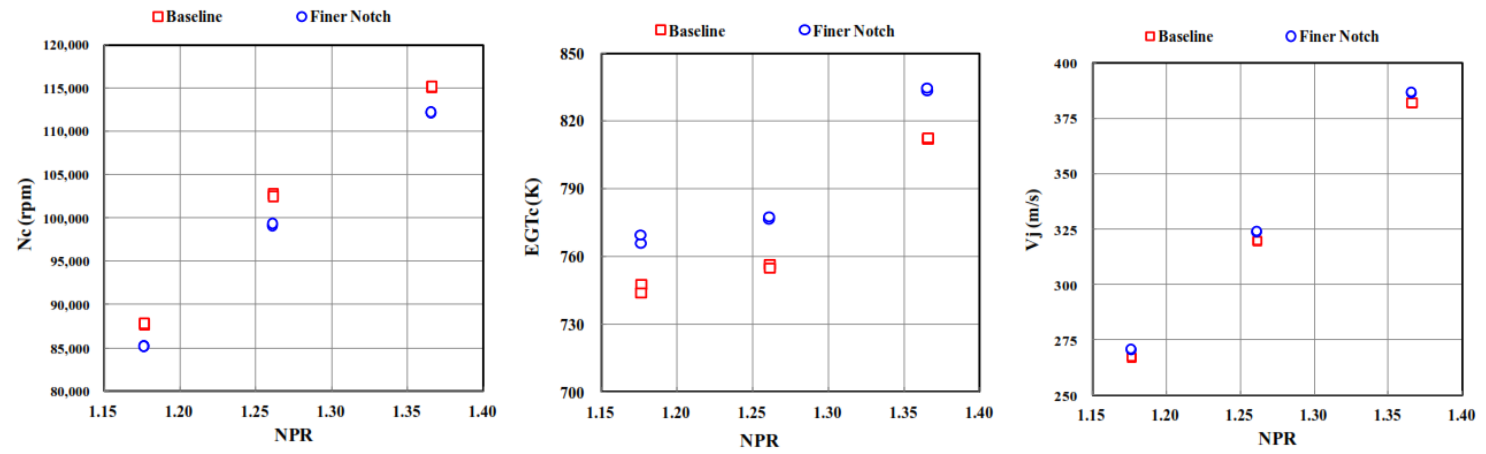

Fig.14. Engine parameters with regard to NPR. Left (a) corrected rotation speed; Middle, (b) corrected exhaust gas temperature (EGT); right, (c) Exhaust velocity.

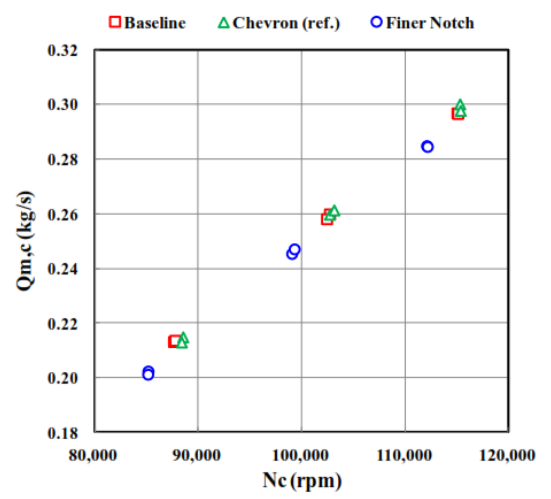

Fig.15.Corrected mass flow rate.

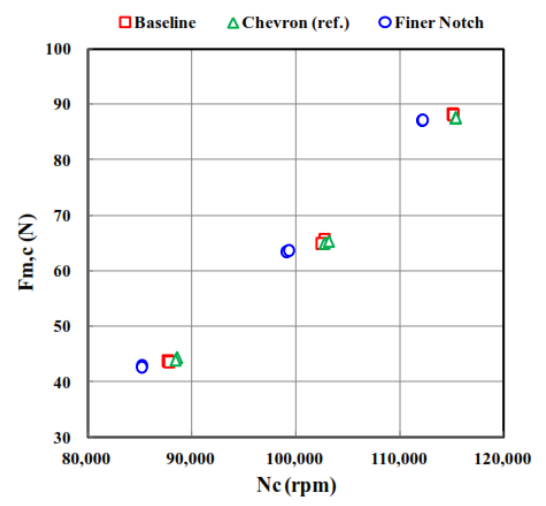

Fig.17. Corrected thrust.

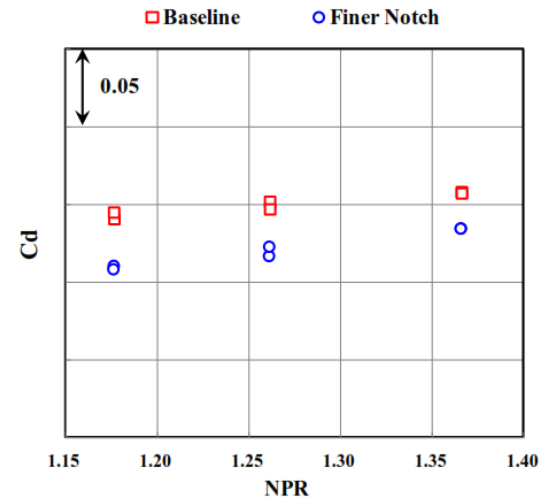

Fig.16. Mass flow rate coefficient.

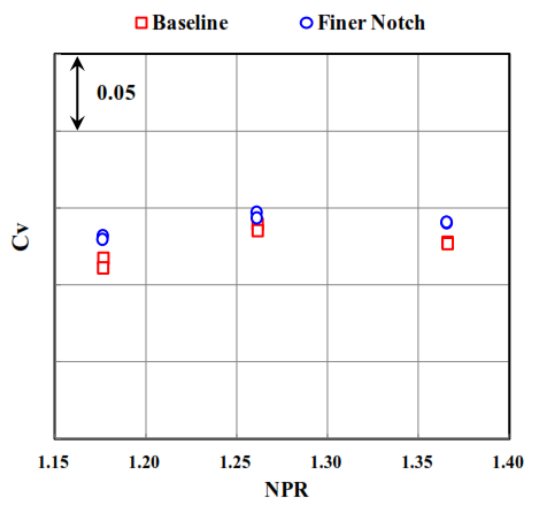

Fig.18. Thurust coefficient 


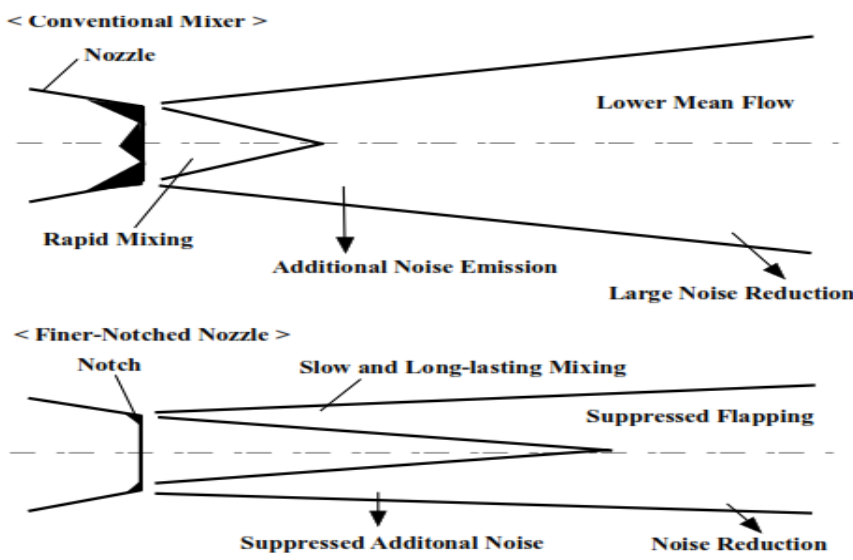

Fig.19. Schematic views of mixing features. Top, Rapid mixing by conventional mixing nozzle; Bottom, small disturbance by notch.

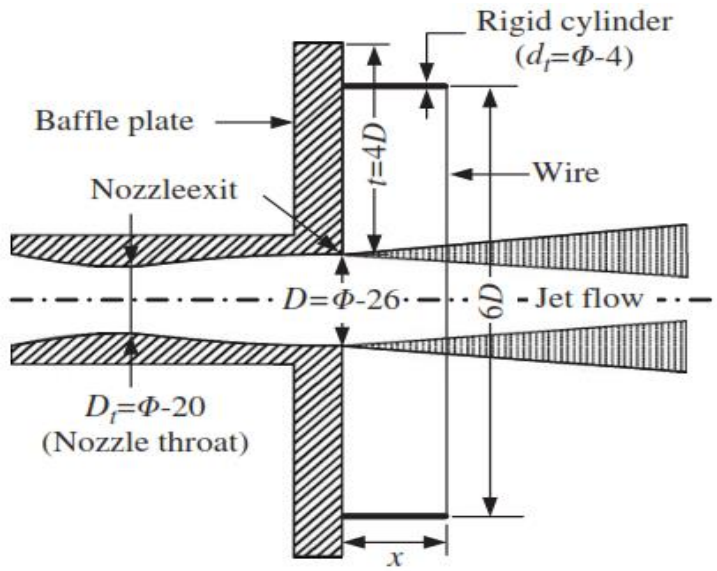

a) Wire device

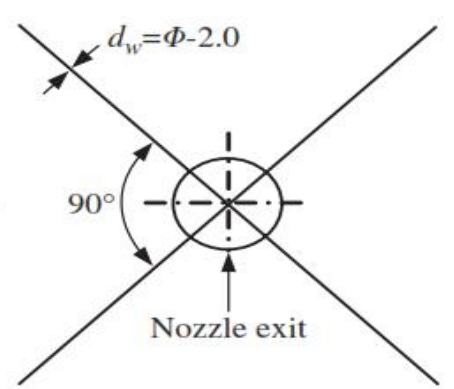

b) Front view

Fig. 20. Arrangement of control wire device.

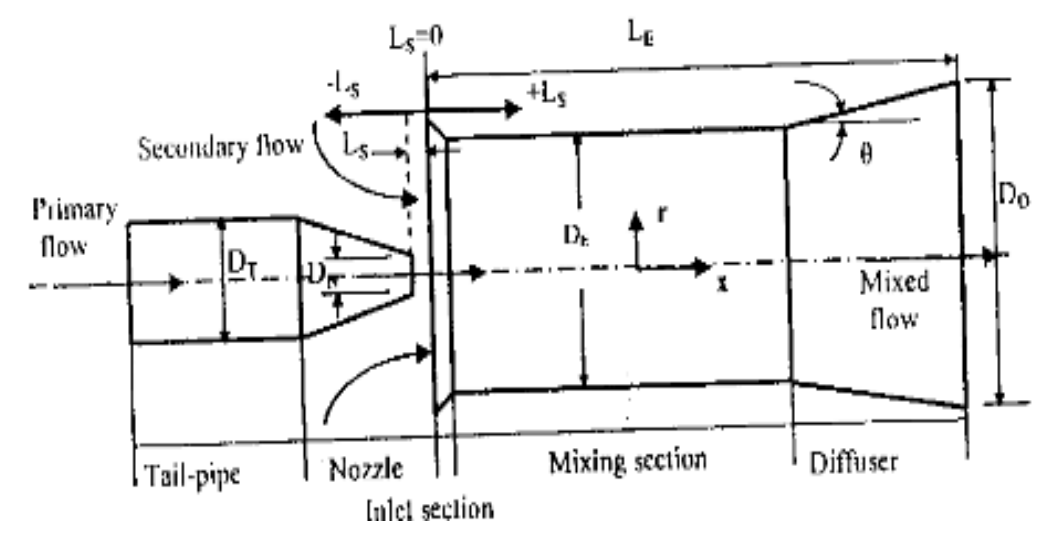

Fig. 21. Ejector geometry with conventional nozzle. 